\title{
Evaluation of the usefulness of serial combination processes for drying of apples
}

\author{
Tim SIEBERT ${ }^{* 1, A}$, Andreas BECKER ${ }^{2, A}$, Mirko BUNZEL ${ }^{2, A}$, Marcus ZUBER ${ }^{3,4, A}$, Elias \\ HAMANN ${ }^{3,4, A}$, Tilo BAUMBACH ${ }^{3,4, A}$, \\ Heike P. KARBSTEIN ${ }^{1, A}$, Volker GAUKEL ${ }^{1, A}$
}

\author{
A: Karlsruhe Institute of Technology (KIT) \\ 1: Institute of Process Engineering in Life Sciences Section I: Food Process Engineering, \\ 2: Institute of Applied Biosciences, Department of Food Chemistry and Phytochemistry \\ 3: Laboratory for Applications of Synchrotron Radiation (LAS), \\ 4: Institute of Photon Science and Synchrotron Radiation
}

Kaiserstrasse 12, Karlsruhe, Germany, 76131

Tel.: +49-721-60848586,E-Mail: tim.siebert@kit.edu

\begin{abstract}
Serial combination drying processes are currently studied as alternatives to conventional drying processes. Compared to freeze-drying (FD), serial combination drying appears to be faster and less expensive, while providing better product quality than hot-air drying (HAD) and microwave-vacuum drying (MVD) as previously demonstrated for carrots. Using the example of carrots, it has also been shown that the drying front moves radially outwards over the course of FD. This unexpected behaviour was suggested to originate from the carrots' heterogeneous structure. It was hypothesized that apple pieces behave differently. Here, this hypothesis was proven by using micro-computed tomography (micro-CT) measurements of partly freeze-dried apple pieces. In order to improve the drying process of apple pieces, several single and combination drying processes were carried out. Processes were evaluated by using drying time and sample quality as relevant parameters. Sample quality was determined by analyzing the 3Dstructure, rehydration behaviour, colour and ingredient retention. Results showed that single MVD is a well suitable drying technique for apple pieces, producing dried products of equal quality to FD. Different from carrots, serial combinations are not necessary to improve the quality of dried apple pieces. Nonetheless, especially a combination of HAD and MVD was useful to obtain specific structures such as puffed pores that did not result from single MVD.
\end{abstract}

Keywords: combination drying, structure, micro-CT, ascorbic acid, apple

The most common processes for drying chunky foods are hot-air drying (HAD), microwave-vacuum drying (MVD) and freeze-drying (FD). As each drying process has unique advantages and disadvantages, new drying strategies are investigated in order to overcome the disadvantages. For example, FD is generally considered to produce high-quality products, but, at the same time, represents the most time-consuming and most expensive drying process ${ }^{[1,2]}$. Serial combination of different single drying processes is a promising strategy to combine both short drying time and high product quality. Various studies ${ }^{[3-9]}$ have shown the usefulness of this technique, which is why other promising processes like ultrasound-assisted drying ${ }^{[10-12]}$, infrared-assisted drying, intermittent drying ${ }^{[13-18]}$ or osmotic pre-drying ${ }^{[19-21]}$ are not investigated in the present study.

Figiel $^{[4]}$ reported that application of a pre-MVD step and post-HAD increases the quality of beetroots concerning rehydration properties and antioxidant activity resulting in quality parameters comparable to FD products. Duan et al. ${ }^{[5]}$ showed that a combination of pre-FD and post-MVD with a changeover point at a relative moisture content of $X / X_{0}=0.4$ produced products with similar rehydration properties as products obtained from single FD. A relative moisture content of $X / X_{0}=0.4$ means that $40 \%$ of the original moisture content is still inside the product. Cui et al. ${ }^{[9]}$ compared a pre-MVD and post-FD process to single FD, MVD, and HAD for the products carrot and apple. They reported much shorter drying times, but comparable shrinkage ratio and rehydration capacity for the product of the combination process compared to FD products.

A complete analysis of all possible two-way combinations of HAD, MVD, or FD with carrots as product and a constant changeover point was undertaken by Rother et al. ${ }^{[8]}$. The authors found that pre-FD processes, which were $25-40 \%$ faster than single FD, led to products that met the freeze-drying standard concerning shape, 
volume, colour and rehydration behaviour. On the other hand, post-FD processes were slower, and samples did not match the quality of FD samples. Possible explanations for the results were the formation of a porous structure during pre-FD and of a diffusional barrier during pre-HAD or -MVD.

Based on these hypotheses, we previously investigated the influence of the changeover point for all reasonable combinations during drying of carrot discs ${ }^{[3]}$. As drying time of a $2^{\text {nd }}$ step of a combination drying process was reduced after FD and prolonged after HAD and MVD, the previously made hypotheses by Rother are supported.

Often, the existence of a porous layer or a crust has only been hypothesized according to indirect measurements of rehydration and drying behaviour. However, more recently we were able to visualize crust formation directly using micro-CT measurements during HAD of carrots ${ }^{[22]}$. Micro-CT measurements were used, because alternatives like nuclear magnetic resonance (NMR) or light microscopy measurements are not as suitable. NMR measurements are especially good in visualizing moisture distributions ${ }^{[23,24]}$, while the structure can only indirectly be visualized. Due to the low moisture content of dry products, a visualization of the structure with NMR is not possible. A good example of this circumstance can be seen in a recent publication by Kamal et al. ${ }^{[25]}$. They air-dried apple slices for different times and analyzed it with a LF-NMR. The resulting images show in great detail the moisture distribution inside the samples, but the longer drying took place, the less is visible on the images. Therefore, structure formation is impossible to observe with LF-NMR. Light microscopy measurements including the analysis of microtome-slices ${ }^{[26]}$ are invasive and have a very limited 2-dimensional field of view making them unsuitable as well for 3-D measurements. On the other hand, micro-CT measurements have already successfully been used in various studies to visualize a products pore structure ${ }^{[27-33]}$. In an additional micro-CT based study ${ }^{[34]}$, we analyzed pre-FD processes of carrots to show the formation of a porous layer around the sample. It was expected that a porous layer forms around the product during FD, leading to a better mass transport in later stages of the combination drying process. Unexpectedly, this theory was not valid for carrot discs. The drying front moved vertically through the central parts of the carrot and, once it reached the top end of the disc, it moved radially outwards. This effect may be due to the heterogeneous pore structure of carrot tissues, which consist of vascular tissue (xylem) in the center and surrounding vascular cambium and mostly secondary phloem. Each tissue type has a distinct structure, which differs in pore size and shape that may lead to different drying speeds and ultimately to the found drying pattern.

Different from carrots, many dried food products such as apples have homogeneous pore structures. It was hypothesized that the shown drying pattern of carrots during FD will not apply to FD of homogeneous apple pieces. Micro-CT measurements of partly freeze-dried apple pieces shown in this publication reveal that the product structure affects the drying performance, thus verifying our hypothesis. Therefore, it is possible that experiments comparable to our previous studies ${ }^{[3,8]}$ but using a homogeneous product have a different outcome. Therefore, selected single and combination drying experiments have been performed to identify the most suitable drying process to dehydrate homogeneous structures such as in apples. As HAD has been described to result in a severe shrinkage of dried samples ${ }^{[8,9]}$, a non-porous structure ${ }^{[35]}$, and damaged pores ${ }^{[36,37]}$ it was not fully investigated. Sample quality was evaluated based on micro-CT, rehydration, colour and ascorbic acid retention measurements.

\section{MATERIALS AND METHODS}

\section{Material}

Studies with partly freeze-dried apples were performed using the apple variety "Jonagold". They were purchased in a local supermarket and further processed on the same day. For all other experiments, apples of the variety Baya ${ }^{\circledR}$ Marisa (Bay 3484) were kindly provided by the Bavarian Centre of Pomology and Fruit Breeding (Hallbergmoos, Germany). Apples of this variety are characterized by an almost completely red coloured pulp, which is caused by a high anthocyanin content. All apples of the variety Baya ${ }^{\circledR}$ Marisa were obtained within three days after harvest.

Apples for FD experiments were directly processed to sample size, vacuum-sealed inside plastic bags and frozen at a temperature of $T_{\text {storage,GT }}=-80{ }^{\circ} \mathrm{C}$ for at least 48 hours. All other apples were stored as a whole in a controlled atmosphere (CA) consisting of oxygen (1\%), carbon dioxide (2.5\%) and nitrogen (96.5\%). Figure 1 illustrates the processing of apples to sample pieces. It consisted of peeling, core removal, slicing, cutting, sorting and washing. Peeling, core removal and slicing were performed with an apple processing device (Figure 1, left), which creates a peeled spiral of apple pulp without core. Then, the created spiral was cut into 10 fractions of approximately the same size with a special cutting device (Figure 1, right). All pieces with a radial length less than $15 \mathrm{~mm}$ were sorted out. To avoid enzymatic browning, the freshly cut samples were submerged in water for few seconds. To remove excessive surface water, water was allowed to drip off for 60 seconds following a gentle treatment with compressed air for 50 seconds. 

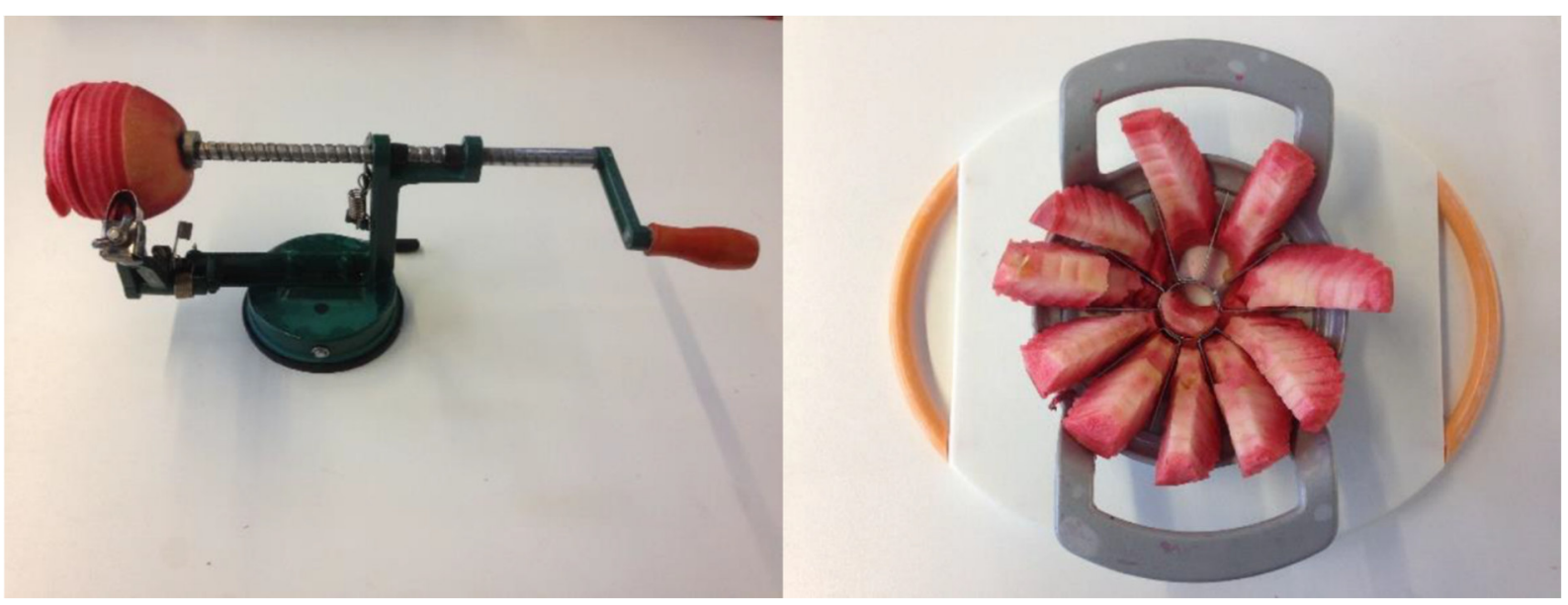

Figure 1: Apple processing prior to drying. Left: peeling, core removal and slicing; right: cutting.

\section{Drying equipment}

Most drying processes were performed using a modular drying processor built in a cooperation with Merk Process (Laufenburg, Germany), which has been described in previous publications ${ }^{[3,8]}$. In summary, the laboratory scale dryer (up to $250 \mathrm{~g}$ of fresh samples) can combine different processes (HAD, MVD, FD) in the same cavity either in a parallel or in a serial way. FD is performed by positioning samples on a rotating plate, MVD and HAD is performed inside a rotating drum. Vacuum can be applied, independently of the product container, to an absolute pressure of $p_{\text {Vacuum }}=0.3 \mathrm{mbar}$. Sample weight and surface temperature were recorded during drying. All drying times are logged, starting at the moment of the first energy input. In order to measure only drying time, times needed to reach the desired pressures during MVD or FD and to weigh the samples are not logged.

FD processes for the micro-CT measurements of partly wet products were conducted using a small production scale freeze-dryer with a horizontally arranged steel tube of $2.5 \mathrm{~m}$ length and a diameter of $0.9 \mathrm{~m}$ (Becker Technologies GmbH, Eschborn, Germany). Inside the chamber, frozen products can be placed on six different levels of heating plates sorted on top of each other. A pirani-sensor (DCP 3000, Vacuubrand GmbH \& co KG, Wertheim, Germany) was used to record the pressure throughout the drying process.

\section{Drying procedure}

All FD processes were conducted with a plate temperature of $T_{\mathrm{FD}}=30{ }^{\circ} \mathrm{C}$ and an absolute pressure of $p_{\mathrm{FD}}=0.3$ mbar. In order to prevent thawing of the samples at the start of the process, the heating plate was cooled until a pressure below the triple point of water was reached. Afterwards, heating was activated. Air speed during single HAD experiments was approximately $v_{\text {air }}=1 \mathrm{~m} / \mathrm{s}$ using two different temperatures $\left(70{ }^{\circ} \mathrm{C}\right.$ and $\left.105^{\circ} \mathrm{C}\right)$. For MVD, pressure was kept at $p_{\mathrm{MVD}}=15 \mathrm{mbar}$. Two different microwave power levels were investigated $(P=250$ and $750 \mathrm{~W})$. A sample load of $m_{\text {sample }}=250 \mathrm{~g}$ was used for all experiments, resulting in effective power levels of $P_{\text {eff }}=1$ and $3 \mathrm{~W} / \mathrm{g}$.

Combination drying experiments were performed using similar parameters as applied previously for carrot drying ${ }^{[3]}$ : drying temperature during a HAD step was $T_{\mathrm{HAD}, \text { comb }}=90^{\circ} \mathrm{C}$, and an effective power level of $P_{\text {eff, }}$ comb $=2 \mathrm{~W} / \mathrm{g}$ was used during a MVD step. FD was always performed using the same process parameters as in the single drying processes. The changeover point was determined using the relative moisture content $X / X_{0}$. Nomenclature of combination processes will follow the order of appearance in the combination and will include the changeover point. For example, a combination process starting with HAD down to a relative moisture content of $X / X_{0}=0.5$, finished by MVD will be described as HAD0.5MVD. All complete single and combination drying processes were conducted in triplicate.

For the analysis of partly dried samples, FD processes were conducted for different drying times $(30,60$ and 120 $\mathrm{min})$. Drying time was started as soon as the final pressure of $0.3 \mathrm{mbar}$ was reached. After their dedicated drying time, all samples were taken out of the dryer, placed into a sealable plastic container and cooled during transport to the micro-CT. 


\section{Micro-CT measurements}

Structure visualization was realized with micro-CT measurements. A custom-made cone beam geometry scanner of the Institute for Photon Science and Synchrotron Radiation (IPS) of the Karlsruhe Institute of Technology (KIT) was used. Using this setup, samples of different scale can be measured in the same device. The cone beam geometry then leads to a certain magnification, depending on the distances between object, source, and detector. With the given setup and the size of the samples, the effective pixel size of the system is around $14 \mu \mathrm{m}$. Each measurement consists of a $360^{\circ}$-rotation of the samples in the x-ray beam with one projection each $0.176^{\circ}$. This leads to 2048 projections over the whole measurement. One projection takes about 2 seconds, which adds up to over 68 minutes for a full measurement. Further details on the scanner have been described in other publications ${ }^{[22,34,38]}$.

The placement of the samples and containers on the positioning unit can be seen in Figure 2A. Apart from the sample containers, some of the high precision positioning electric motors that can move and tilt the samples in every direction are visible below. In Figure 2B, sample positioning inside the micro-CT chamber can be observed. Directly to the left of the samples is the $\mathrm{x}$-ray tube, while the detector is still partly visibly at the right border of the figure.

During the measurement of the partly frozen samples, product containers were located in the central level of a three-level Perspex container. In the levels above and below, dry ice was used to cool the samples throughout one measurement to prevent thawing. For pictures and more information about this method please see a previous publication $^{[34]}$. For all investigated processes, at least three measurements for different samples of one batch were conducted.

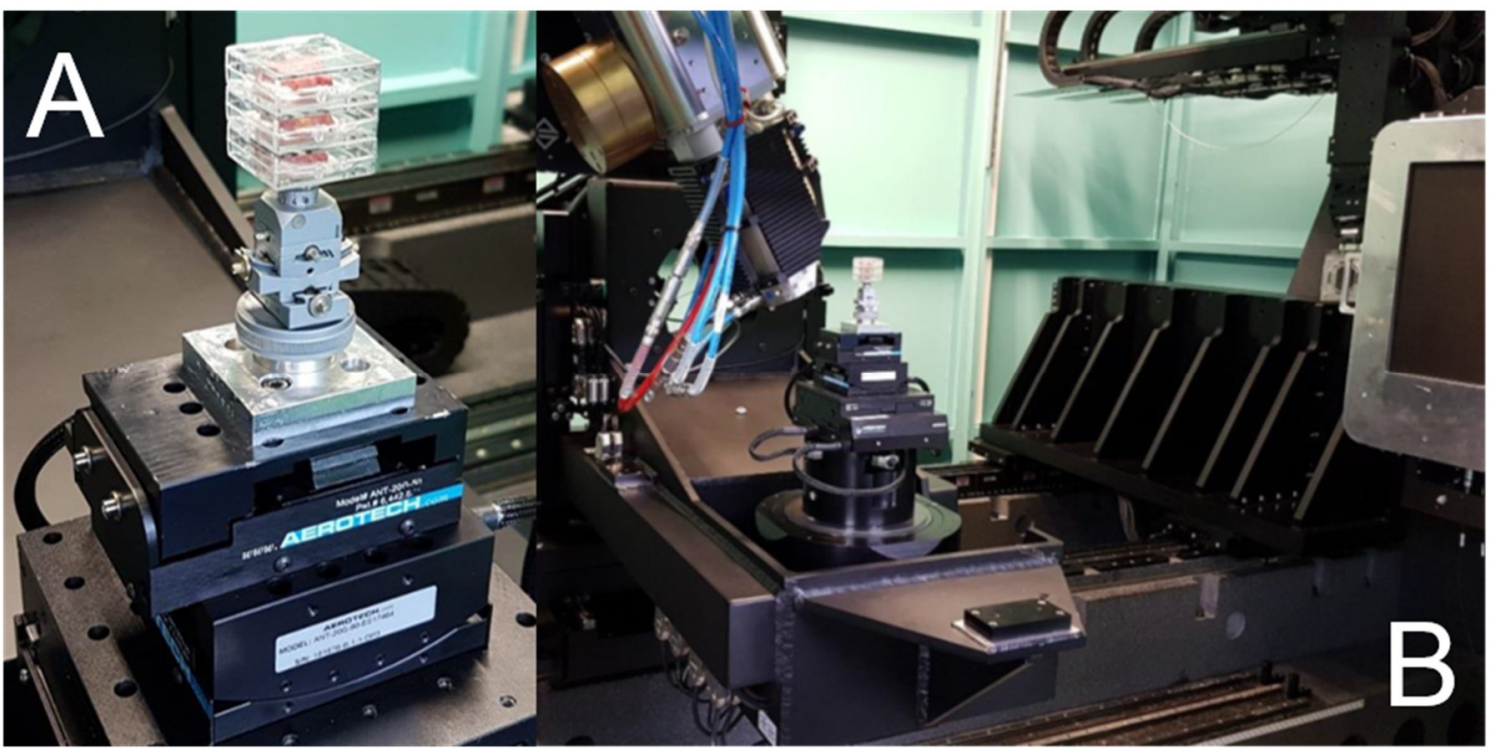

Figure 2: Placement of samples: on positioning unit (A) and in the whole micro-CT chamber (B).

\section{Sample analysis - ascorbic acid retention}

Ascorbic acid is generally sensitive to food processing operations and therefore easily degraded during drying and other thermal and non-thermal processes. The degradation rate is depending on temperature, $\mathrm{pH}$, light and the presence of enzymes and redox-active metal ions ${ }^{[39]}$. Therefore, ascorbic acid is widely used as a general quality parameter to study ingredient retention.

All chemicals used were of analytical grade if not stated otherwise. Dithiothreitol was from Serva, ascorbic acid and ammonium-acetate from Fluka, acetonitril from VWR, EDTA from Lancaster and meta-phosphoric acid (39-43\% stabilized with $\mathrm{NaPO}_{3}$ ) from Alfa Aesar.

The samples obtained after drying were immediately placed into a vacuum bag and stored at $-80^{\circ} \mathrm{C}$ until further analysis. For each experiment, corresponding fresh samples were taken before drying, immediately frozen, and stored and analyzed in the same way as the dried samples.

Homogenization was performed using an IKA Tube Mill control (Staufen, Germany): samples were frozen in liquid nitrogen and directly milled for a maximum time of one minute to prevent thawing of the samples. The homogenized samples were stored at $-80^{\circ} \mathrm{C}$ until analysis. For the analysis of ascorbic acid, $\sim 1 \mathrm{~g}$ of fresh or 
$\sim 0.15 \mathrm{~g}$ of dry sample material was precisely weighed into brown $15 \mathrm{ml}$ plastic centrifuge tube and kept on ice during the whole analysis to prevent thermal degradation of ascorbic acid. After addition of $10 \mathrm{ml}$ of a $3 \% \mathrm{meta}$ phosphoric acid solution $(\mathrm{w} / \mathrm{v})$ containing $1 \mathrm{mM}$ EDTA, samples were shaken and placed into a cooled ultrasonic bath for 15 minutes. Afterwards the samples were vortexed for 30 seconds and kept on ice for another 15 minutes. After centrifugation $\left(10\right.$ minutes, $4.000 \mathrm{rpm}, 4{ }^{\circ} \mathrm{C}$ ) the supernatant was membrane-filtered (MachereyNagel, RC $0.45 \mu \mathrm{m}, \varnothing 25 \mathrm{~mm}$ ). To determine total ascorbic acid, $1 \mathrm{ml}$ of the extract was mixed with $0.2 \mathrm{ml}$ of a $2 \%$ solution $(\mathrm{w} / \mathrm{v})$ of dithiothreitol in water. The solution was left standing in the dark for two hours to completely reduce dehydroascorbic acid to ascorbic acid ${ }^{[40]}$. An aliquot of the extract $(20 \mu \mathrm{l})$ was mixed with $10 \mu \mathrm{l}$ of $200 \mathrm{mM}$ ammonium-acetate and $170 \mu \mathrm{l}$ of acetonitril to prevent peak distortion during chromatography. Chromatographic analysis was performed by HPLC-DAD (LC-20AT pumps, SIL-20AC autosampler, CTO20AC column oven, SPD-M20A diode array detector; Shimadzu) using a Luna-HILIC column $(250 \times 4.6 \mathrm{~mm}$, $5 \mu \mathrm{m}, 200 \AA$, Phenomenex) as suggested by Tai \& Gohda $2007^{[41]}$. Separation was carried out at $30^{\circ} \mathrm{C}$ applying an isocratic flow of acetonitril/water/100 mM ammonium-acetate 86/4/10 (v/v/v) with a flow rate of $1.2 \mathrm{ml} / \mathrm{min}$. UV-detection was performed at $268 \mathrm{~nm}$, the injection volume was $100 \mu 1$. Linear ten-point external calibration curves were prepared using ascorbic acid concentrations ranging from $5.9-58.4 \mu \mathrm{M}$.

Total ascorbic acid contents of fresh samples were calculated as mg ascorbic acid/100 g sample. For the calculation of total ascorbic acid contents in dried samples the weighed in, analyzed portion $(m)$ was calculated back to the corresponding fresh weight according to formula (1). This calculation assumes that the amount of dry matter remains constant during the drying process.

$$
\text { corresponding fresh sample weight }[\mathrm{g}]=m * \frac{1-X_{\mathrm{wb}} \text { (dried sample) }}{1-X_{\mathrm{wb}(\text { fresh sample) }}}
$$

\section{Sample analysis - moisture content}

Moisture content $\mathrm{X}$ on a dry basis was measured for fresh and dry samples. Therefore, they were chopped into small pieces of $1 \mathrm{~mm}^{3}$ and placed in a drying cabinet at $85{ }^{\circ} \mathrm{C}$ until constant weight, but at least for 24 hours. Before and after drying, the samples were weighed to determine the initial $\left(\mathrm{m}_{\mathrm{wb}}\right)$ and dry mass $\left(\mathrm{m}_{\mathrm{db}}\right)$ of the sample. Afterwards, $\mathrm{X}_{\mathrm{db}}$ was calculated according to formula 2.

$$
X=\frac{m_{\mathrm{wb}}-m_{\mathrm{db}}}{m_{\mathrm{db}}}
$$

\section{Sample analysis - rehydration properties}

In order to evaluate rehydration properties, five dried sample pieces were weighed and submerged in a $500 \mathrm{ml}$ glass with hot demineralized water of constant temperature $\left(t_{\text {water }}=80^{\circ} \mathrm{C}\right)$. Submersion was ensured by use of a tea strainer and was kept for different rehydration times $\left(t_{\mathrm{r}}=1,2,3,5,10,20,40\right.$ and 60 minutes). The apple pieces were removed from the submersion bath but kept in the tea strainer for one min to provide time to drip off excess surface water. Finally, the sample pieces were weighed and the water absorption coefficient (WAC) was calculated. The WAC was introduced by Le Loch-Bonazzi et al. ${ }^{[42]}$ and named by Lewicki ${ }^{[43]}$. It describes the ratio calculated as the amount of water absorbed during rehydration divided by the amount of water lost during drying. Therefore it describes, how much of the water that was lost during drying can be reintroduced into the dried sample.

\section{Sample analysis - Colour values}

Changes of the sample colour were documented using photographs of 10 different product pieces. Pictures were taken with a digital camera (EOS 700D, Canon, Tokyo, Japan) inside a light box with standardized lighting. The colour temperature of the light box was $5500 \mathrm{~K}$. Photographic parameters were an exposure time of $t_{\text {exposure }}=0.125 \mathrm{~s}$, an aperture value of $f=18$ and an ISO value of 100 . Taken pictures were in the RAW-format (CR2) and subsequently converted into the tagged image file format (.tif) with the freeware program IrfanView (Irfan Skiljan, Wiener Neustadt, Austria). In order to segment the parts of the pictures with apple pieces only, a colour thresholding was performed using Image ${ }^{[44]}$ via the distribution Fiji ${ }^{[45]}$. Once only the apple pieces were selected, median values for RGB-values (Red, Green, Blue) were measured. As RGB values are device specific, they were converted to $L^{*} a * b *$-values. $L *$ represents a samples brightness and can adapt values between 0 (black) and 100 (white). The $\mathrm{a}^{*}$-value represents the complementary colours red (positive values) and green (negative values). The last value $b^{*}$ covers the complementary colours yellow (positive values) and blue (negative values). As only positive values were measured for this product, $\mathrm{a}^{*}$ describes the redness and $\mathrm{b}^{*}$ the 
yellowness of a sample. A higher value therefore corresponds to a more intense colour. If a difference in either of the colour values is mentioned in the results and discussion section, it was significantly different.

\section{Sample analysis - image processing}

Sample analysis for image processing was conducted in analogy to two previous investigations ${ }^{[22,34]}$. Micro-CT data was reconstructed with Octopus 8.9 (Inside Matters, Gent, Belgium) and further processed using ImageJ. Processing consists of histogram equalization, a reduction to 8-bit and application of a denoising algorithm ${ }^{[46,47]}$. Finally, if needed, the stack was rotated in such a way that the narrow side of the samples always faced the upside in the X-Y-plane. This procedure results in an 8-bit greyscale stack of virtual horizontal cuts through the product. In order to get a 3-dimensional impression of the sample, ImageJ can calculate the orthogonal views to the horizontal cuts. A schematic drawing of all points of view is given in Figure 3. All other pictures of samples are presented in this way, too.

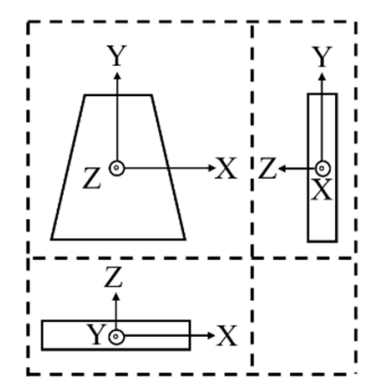

Figure 3: Outline of the spatial directions of all measured sample planes.

In order to effectively analyse the data in a quantitative way concerning values like pore-size distribution or porosity, an automatic evaluation routine is crucial, because a manual approach would be far too timeconsuming. Therefore, after a binarization of the pictures, an effective denoising algorithm has to be applied, which typically not only deletes noise pixels, but wall structures as well. This leads to an unwanted "opening" of pores in case of very thin cell walls. This artifact can possibly be corrected using a closing algorithm. These algorithms (e. g. watershed algorithms) are typically well suited for round pore types. We tried to evaluate the data in a quantitative way using ImageJ, but we were not satisfied with the quality of the closing algorithm, because it created too many wrong pores. Therefore, the presented micro-CT measurements are interpreted in a qualitative way to visualize differences of the drying pattern.

Statements about pore sizes rest on manual measurements of selected pores using ImageJ. Therefore, after zooming into the pore, a straight line was drawn from on boundary of the pore to the opposite one. If the pore was not round, it was made sure to use the longest possible diameter. In this manner, 20 of the biggest pores and 20 of the smallest visible pores were analyzed. With these measurements, the dimensions of the pores could be narrowed down to a certain range. Quantitative information based on an automated measurement routine were not possible due to the previously mentioned reasons.

\section{Statistical Analysis}

Rehydration and ingredient retention data were submitted to statistical analysis. OriginPro $2017 \mathrm{G}$ was used in order to verify a significant difference for corresponding data points. Therefore, a one way analysis of variance (ANOVA) was conducted in combination with Scheffe's test at a significance level of $\alpha=0.05$.

\section{RESULTS AND DISCUSSION}

\section{Drying times of different drying processes}

Drying times for selected single and combination drying processes of apples are given in Table 1 (left side) in comparison with drying times of carrots from a former study (right side). FD in general is by far the longest single drying process ( $300 \mathrm{~min}$ for apples and $285 \mathrm{~min}$ for carrots), while the drying time of MVD depends on the power and the drying time of HAD depends on the temperature level. MVD at $250 \mathrm{~W}$ is over two times faster (112 min for apples and $127 \mathrm{~min}$ for carrots) than FD and has a relatively small standard deviation. Differently, drying times for MVD at $750 \mathrm{~W}$ (mean: 68 min for apples) show a high deviation of 25 min. Analysis of incoming and reflected microwave power revealed a high amount of reflection for trials 2 and 3 . The exact 
reason for this behaviour is currently unknown. It has been documented for the drying of carrots with the same processor $^{[48]}$ that the amount of absorbed microwave energy is constant over the complete process for a power input of $250 \mathrm{~W}$. During MVD with a power input of $750 \mathrm{~W}$, the amount of absorbed microwave energy decreases towards the end of the process because there is not enough water left in the product. This variation of absorption may result in a higher variance during the process, which could explain higher deviations for drying times.

Table 1: Drying times of selected single and combination processes with apple pieces and carrots as product.

\begin{tabular}{|l|r|r|r|r|}
\hline Product & \multicolumn{2}{|c|}{ Apples } & \multicolumn{1}{|c|}{ Carrots $^{[3]}$} & \\
\hline Process & $\begin{array}{l}\text { Mean value } \\
\text { min }\end{array}$ & $\begin{array}{l}\text { Standard } \\
\text { deviation / min } \\
\text { / min value }\end{array}$ & $\begin{array}{l}\text { Standard } \\
\text { deviation / min }\end{array}$ \\
\hline & & & & - \\
\hline MVD 250 W & 112 & 5 & 127 & 1 \\
\hline MVD 750 W & 68 & 25 & 23 & - \\
\hline HAD 70 ${ }^{\circ} \mathrm{C}$ & 283 & 12 & 240 & 15 \\
\hline HAD 105 ${ }^{\circ} \mathrm{C}$ & 175 & 5 & 146 & 18 \\
\hline FD & 300 & 0 & 285 & 2 \\
\hline HAD0.5MVD & 95 & 8 & 78 & 19 \\
\hline HAD0.5FD & 186 & 9 & 272 & 194 \\
\hline FD0.5HAD & 209 & 16 & 194 & \\
\hline
\end{tabular}

In general, drying times match findings from our previous study on drying of $\operatorname{carrots}^{[3]}$ (Table 1, right side), which is especially interesting for FD. As previously mentioned, it was found that carrots dried heterogeneously. Drying of apples, on the other hand, was hypothesized to be homogeneous, reflecting the homogenous, parenchymatous accessory tissue ("cortex") of apples. As drying times are comparable for both products, the heterogeneous structure of carrots may solely affect the drying pattern during FD, but has no influence on the overall drying time. In case of MVD, an increase of the power level had a bigger effect for carrots compared to apples. This could be a result of the previously mentioned high reflection values that were observed during the $750 \mathrm{~W}$ experiments with apples. HAD0.5MVD was 17 min faster for carrots as well. An explanation for this finding could not be found. On the other hand, HAD0.5FD was 86 min longer with carrots as product. This could be explained with different amounts of crust formation for different products. Apples tended to stick to the surface of the rotating drum inside the modular drying processor, thus developing a crust only at 5 out of 6 possible sides of the piece. Carrots did not stick to the walls and developed a crust around all sides, which worked as a diffusion barrier during FD, thus prolonging the process. In case of HAD0.5MVD, this circumstance is irrelevant as MVD is not limited by mass transport ${ }^{[48]}$.

\section{Drying pattern during FD}

In order to demonstrate the differences between the drying patterns, Figure 4 illustrates the structure of different apple pieces after they were freeze-dried for different periods of time. Bright structures represent dense structures such as ice or pore walls, while dark structures represent loose structures deriving mostly from airfilled pores or the surrounding air. The bright semi-circle in the picture of the $30 \mathrm{~min}$ dried sample (Figure 4, left) is due to a wall of the plastic container, in which the sample was placed. After 30 minutes, the sample itself is almost completely filled with ice, although a natural porosity with air filled pores can be seen as dark spots in all planes. After 60 minutes of FD, a thin dry layer around the whole sample is visualized as a darker area representing air filled pores around the solid and bright central part. The drying front develops homogeneously around the product: after 120 minutes of FD, the dry layer around the sample is significantly thicker.

Only very few areas of the sample surface are not dry after 120 minutes of FD; for example, the left side of the sample (still solid and therefore bright; visible in both the X-Y-and the X-Z-planes). This might be due to a direct contact of the analyzed sample to another sample on the drying tray. The contact between the samples potentially changes the drying behavior in a way as if both samples were one large sample, resulting in lingering moisture at the connected surface. The drying front at the bottom of the sample (down side in X-Z-plane or right side in Y-Z-plane) is almost a straight line. Only the end points are directed upwards towards the top of the sample, potentially due to the heat application from below. As the bottom of the sample is blocked, mass transfer resistance is probably lower at the sides of the sample. This leads to a drying progress from bottom to top of the sample as well as from the sides on inward resulting in a diagonal drying front at the edges of the sample.

Overall, the drying front is developing inwards with increasing drying time. This contrasts findings from FD of carrots $^{[34]}$, demonstrating that the central parts of the carrot samples dried first. Subsequent to dehydration of the 
central parts, drying proceeded radially outwards. As previously mentioned, these differences in drying behaviour are most likely due to the different tissue structures of carrots and apples. While carrots are heterogeneous, consisting of vascular tissues and ground tissue (secondary phloem), the commonly consumed apple tissue is homogeneous and consists of parenchyma cells and intercellular spaces, arranged in a net-like pattern $^{[49]}$. Therefore, the different drying pattern for carrots is solely based on their heterogeneous structure, while apple drying follows the common FD theory.

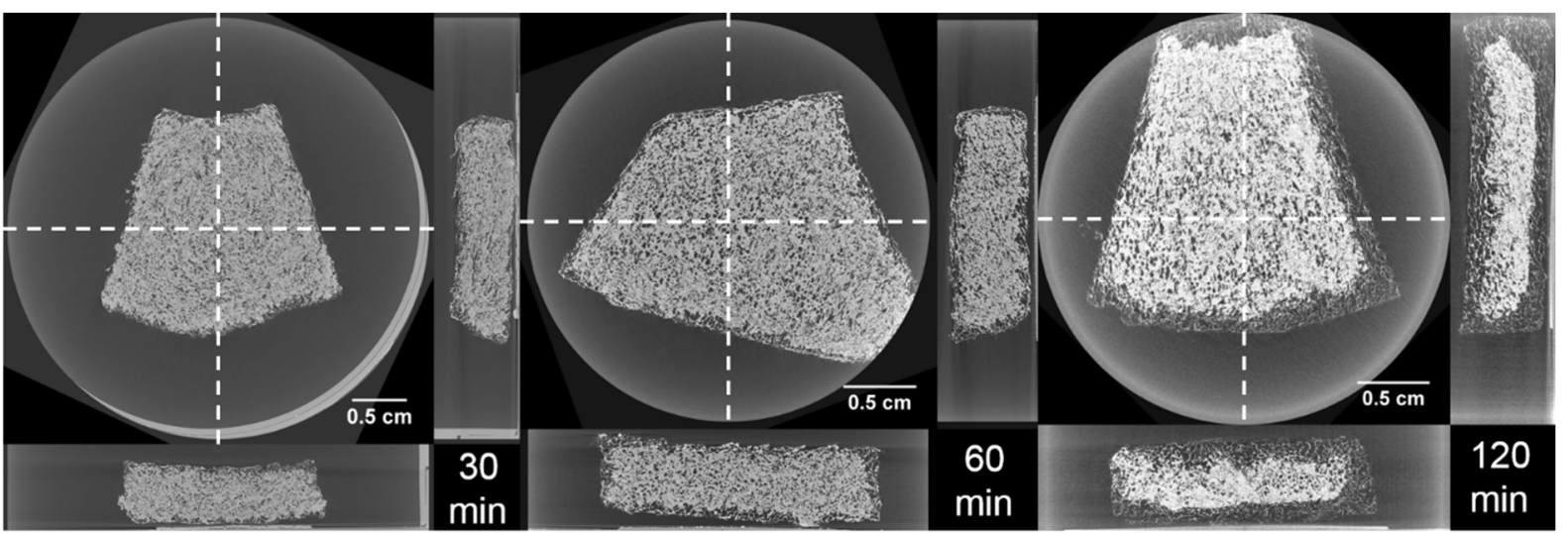

Figure 4: Partly dried apple pieces after 30 (left), 60 (middle) and 120 (right) minutes of FD measured with micro-CT.

\section{Evaluation of drying processes - Micro-CT measurements}

After demonstrating that homo- and a heterogeneous samples show different drying patterns during FD, it should be clarified whether combination drying processes are superior to single drying processes. Figure 5 shows dry apple samples of FD (left) and MVD processes with a power input of $250 \mathrm{~W}$ (middle) and $750 \mathrm{~W}$ (right). All structures in Figure 5 are largely comparable, showing pore sizes in the micrometer range. The pore sizes of the obviously largest and smallest pores were manually measured using ImageJ. As described in the materials and methods section, no statistically sound automated method could be established, but according to the manual measurements, no values outside the apple cell boundaries described in literature $(50-500 \mu \mathrm{m})^{[49]}$ were found. Furthermore, their shape still resembles the fresh state before drying. Differences include a minor deformation of the FD sample and a denser surface of the MVD samples. The dense structure at the tip of the $750 \mathrm{~W}$ sample was visually identified as remaining apple core tissue. It did not show any signs of thermal damage, but the structure was much denser compared to the rest of the tissue. Usually FD samples do not show signs of shrinkage or deformation, as demonstrated for carrots ${ }^{[3,8,9,34]}$ and apples ${ }^{[9,50,51]}$. Therefore, deformation of the FD sample most likely occurred after the process. As the FD sample had a sponge-like appearance, post-process storage in a vacuum bag in combination with applied contact pressure during preparation for micro-CT measurements may result in sample structure alteration. MVD samples were not deformed, potentially due to their denser surface. Therefore, a denser surface may increase the physical stability of a sample. With an increase of the power level, the crust appears to become thicker and more solid. MVD samples do not show signs of puffing (Figure 5). Puffing basically describes expanded pores in MVD treated samples, resulting from a higher evaporation rate inside the sample compared to the rate of steam transportation from the inside to the sample surface ${ }^{[48]}$. Consequently, pressure is built-up, eventually leading to a pore expansion as previously shown for carrots by using micro-CT pictures ${ }^{[34]}$. As this does not apply to the apple samples, the dense surface structure may not be able to sufficiently reduce steam transport in order to realize a pressure build-up. Another reason could be that the existing thin crust developed too late during the process when evaporation was already decreasing.

In difference to from findings in literature, pore walls during FD seem to be intact, although the general structure experienced some deformation as indicated before. Lewicki and Pawlak ${ }^{[36]}$ investigated the influence of drying on the microstructure of apple tissue. They used a microtome to slice dried apple tissue and a microscope to visualize the pores. Freeze-dried samples had several broken cell walls, which is not in agreement with our micro-CT data. However, cell wall destruction is more likely to occur due to the slow freezing process prior to drying than to the actual drying process. Lewicki and Pawlak used $-18{ }^{\circ} \mathrm{C}$ as freezing temperature, whereas samples here were frozen at $-80^{\circ} \mathrm{C}$. It has been shown that slow freezing results in larger ice crystals that grow out of cell, thus damaging the cell wall ${ }^{[27]}$. 


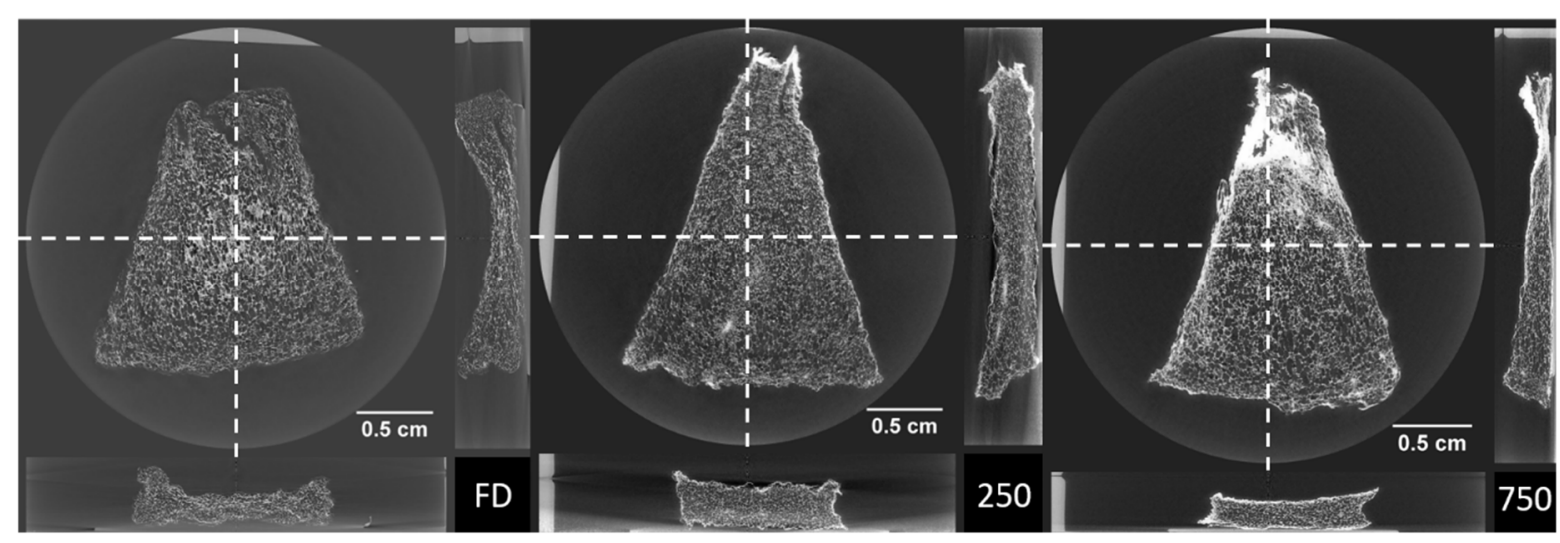

Figure 5: Dried apple pieces after a FD (left) and a MVD process with 250W (middle) and 750W (right) measured with micro-CT.

\section{Evaluation of drying processes - Rehydration measurements}

Because FD and MVD processed samples only differ in the formation of a thin crust around the sample (Figure 5), rehydration properties of MVD samples should be comparable to FD samples, although the thin crust may slightly slow down rehydration. The rehydration behaviour of selected samples prepared by using single step processes 5 (MVD $250 \mathrm{~W}$ and FD) and selected combination processes (HAD0.5FD, HAD0.5MVD) are shown in Figure 6 as WAC over rehydration time. To ensure a high clarity, single drying processes are shown in Figure 6A (left) and combination drying processes are shown in Figure 6B (right). In terms of rehydration capacity, there is only a small, yet significant difference, between both single drying processes. After 60 minutes, MVD samples rehydrated to about $55 \%$ and FD samples to about $57 \%$ of their original moisture content. The main difference between the samples of both processes is the rehydration rate, with FD samples rehydrating faster than MVD samples. This is most obvious for rehydration times of 2, 5 and 10 minutes, where significant differences in the WAC values between the samples of both processes exist (WAC values after 1 and 3 minutes are not significantly different). Exemplarily, after 5 minutes of rehydration, FD samples have already rehydrated to about $40 \%$ of their original moisture content, while MVD samples only rehydrated to about $30 \%$. All WAC values of samples treated with $750 \mathrm{~W}$ (data not shown) were slightly lower than the corresponding WAC values of samples treated with $250 \mathrm{~W}$, but the differences were not statistically significant. Thus, the experimental data confirm our above mentioned hypothesis based on the assessment of the structure.
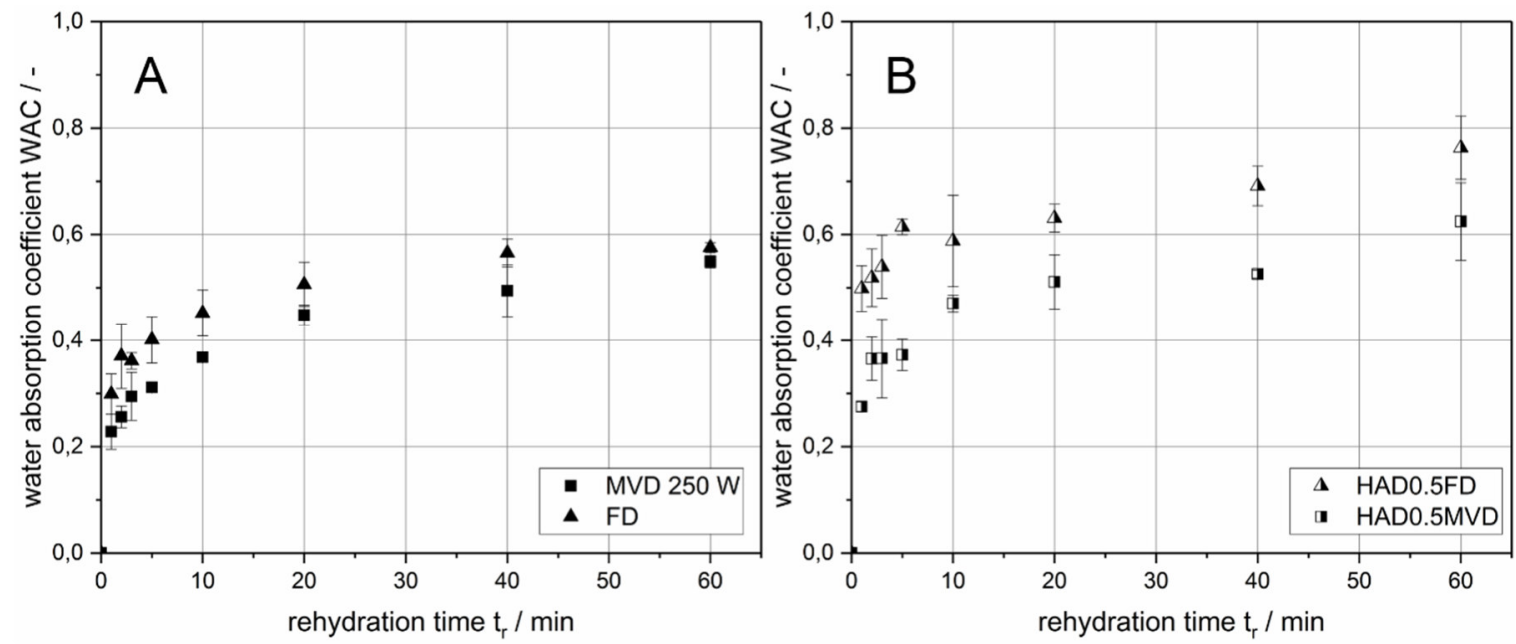

Figure 6: Rehydration behavior of selected single (left, FD and MVD with $250 \mathrm{~W}$ ) and combination (right, HAD0.5FD and HAD0.5MVD) dried apple pieces, shown as WAC over rehydration time.

\section{Evaluation of drying processes - Colour measurements}

Because surface modifications such as crust formation are often associated with a change of colour, colour values were measured. $\mathrm{L}^{*}, \mathrm{a}^{*}, \mathrm{~b}^{*}$-colour values of fresh and dried apple pieces are given in Figure 7 . The colour values of fresh apple pieces suggest a bright red colour, as indicated by high red $\left(\mathrm{a}^{*}\right)$ and low yellow $\left(\mathrm{b}^{*}\right)$ values. The general appearance of MVD processed pieces was more saturated and of a slightly darker colour in between 
red and purple. Colour values support this finding, as the red value is constant, while brightness (L*) and yellow values are 18 and $43 \%$ lower. Hence, red is more dominating for this dried product. FD processed samples appear less saturated as brightness is constant, while red is 16 and yellow is even $57 \%$ lower compared to the fresh sample. Based on a subjective visual inspection of the samples, the colour of MVD samples was, due to its high red saturation, more appealing than the colour of FD samples and even more appealing than the colour of fresh samples.

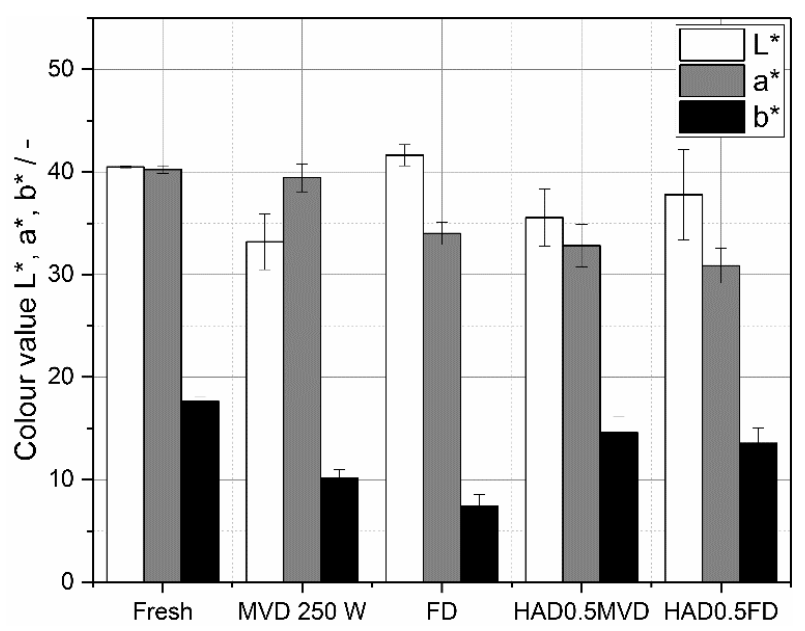

Figure 7: $L^{*}, a^{*}, b^{*}$ - color values for fresh and selected dried apple pieces. From left to right, fresh sample, samples from MVD with $250 \mathrm{~W}, \mathrm{FD}, \mathrm{HAD} 0.5 \mathrm{MVD}$ and HAD0.5FD.

\section{Evaluation of drying processes - Ingredient retention measurements}

Apart from structural and rehydration properties as well as colour, chemical properties such as ingredient retention are important parameters to choose a suitable process. Because different drying processes cause different thermal stresses, the retention of valuable constituents such as ascorbic acid is likely to depend on the drying process used. Retention data of ascorbic acid for the different drying processes are given in Figure 10. About $80 \%$ of the initial ascorbic acid content is found in the FD processed product. The mean retention values of ascorbic acid after MVD were $87 \%$ and $95 \%$ for MVD250W and MVD750W processes, respectively. Values from literature support found values for MVD. Cui et al. ${ }^{[9]}$ reported an ascorbic acid retention value of $89 \%$ for a MVD process with $2 \mathrm{~W} / \mathrm{g}$ and apples as product. This value is between the documented values for $250 \mathrm{~W}(1 \mathrm{~W} / \mathrm{g})$ and $750 \mathrm{~W}(3 \mathrm{~W} / \mathrm{g})$ from the presented study. In contrast to Cui et al., who documented a very high ascorbic acid retention (97\%) in their publication, in the presented study, retention values of MVD appear to be higher compared to FD. A statistical analysis revealed no significant differences among the retention values of the applied single step drying processes (see Figure 10). Therefore, it can be stated that both FD and MVD lead to a high retention of ascorbic acid without a significant difference.

According to the assessed physical and chemical quality parameters, freeze- and microwave-vacuum-dried apple samples do not differ much. The colour of samples after MVD is even more appealing compared to FD samples. This leads to the conclusion, that neither a FD, nor a combination drying process is reasonable to dry homogeneous products like apples, because a MVD process is sufficient or even better suited.

\section{Evaluation of serial combination drying processes - Micro-CT measurements}

Although the analyzed quality parameters were comparable for MVD and FD samples, specific applications of the dried products may require a different type of quality in terms of product structure. FD and MVD samples show a connected structure of pores of approximately the same size (Figure 5). When it comes to resistance of the dry product against physical forces during mixing with other products in cereals or during storage in a rigid product container, other structures could be beneficial. Puffed products are of interest in applications such as apple chips to be sold as snacks. Previous studies report puffing of apples using special technique called "explosion puffing",[52,53]. This technique uses heating of pre-dried samples up to $90{ }^{\circ} \mathrm{C}$ under atmospheric conditions. When equilibrium is reached, an evacuated vacuum chamber is connected via decompression valves to enable a rapid pressure drop in the sample chamber. This procedure is conducted repeatedly for up to 9 times $^{[53]}$, which reveals the disadvantage of the method. Considering the technological difficulties, a continuously operating explosion puffing drier is hard to accomplish. Furthermore, a new type of dryer is needed 
in order to perform this technique. Sham et al. ${ }^{[35]}$ reported a higher puffing effect during MVD of apple chips if reduced pressure was applied (9 mbar compared to 37 mbar). Scanning electron micrographs, however, did not visualize an increase of pore sizes. It is possible that minor puffing occurred, widening existing pores slightly, but puffing pores are usually much larger than regular pores ${ }^{[34]}$.

A thicker crust around the dried apple samples may thus improve both stability and a possible puffing effect. However, both minimum crust thickness enabling puffing and ideal crust formation parameters are unknown for the used apple variety. A previous study analysing crust formation around carrot slices ${ }^{[22]}$ showed that a $50 \%$ reduction of the relative moisture content by using HAD is sufficient to form a crust around the sample. In a first approach, a HAD0.5FD process was tested to form a crust around an apple sample. The structure of three exemplary dried samples of the combination process are presented in Figure 8.

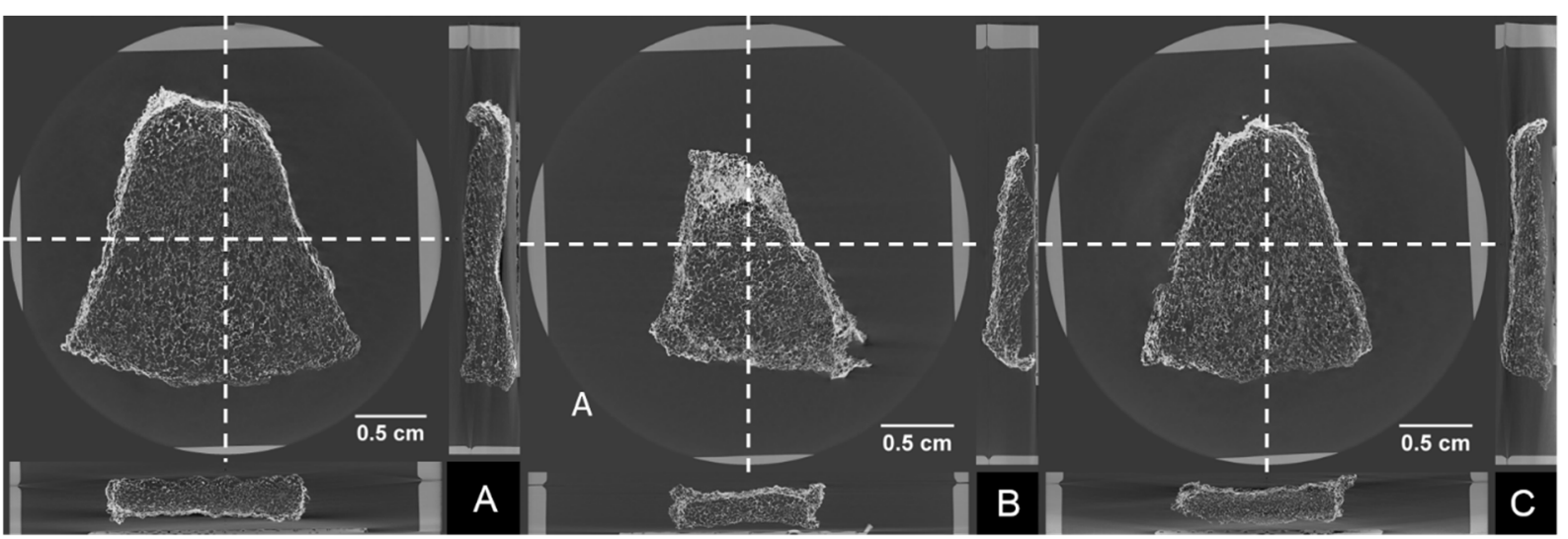

Figure 8: Apple pieces after a HAD0.5FD combination drying process measured with micro-CT.

All three samples have dense structures at the boundaries of next to all sides. The absence of a crust on one of the flat sides (A upside, B and $\mathrm{C}$ downside in the X-Z-layer) can be explained with contact to the drying drum. Although the drum rotates, many samples stick to the inner wall during drying, therefore exposing only one of their flat sides to the hot air. When the samples were taken out of the drum, it was observed that the side, which stuck to the drum was still wet, while the opposite side was already dry. Furthermore, it appeared for all samples that the narrow side (upside in the X-Y-layer) has dried further than the opposite side (downside in the $\mathrm{X}$-Ylayer). This might be explained with the geometrical difference between the two parts leading to a higher areato-volume-ratio and thus a faster drying of the narrow side.

These data show that application of combination drying processes involving HAD is advantageous over single MVD in forming a thicker a crust around a sample. Subsequently, the HAD0.5MVD process was performed in order to validate whether the built crust enables puffing. Structures of the corresponding samples are shown in Figure 9.

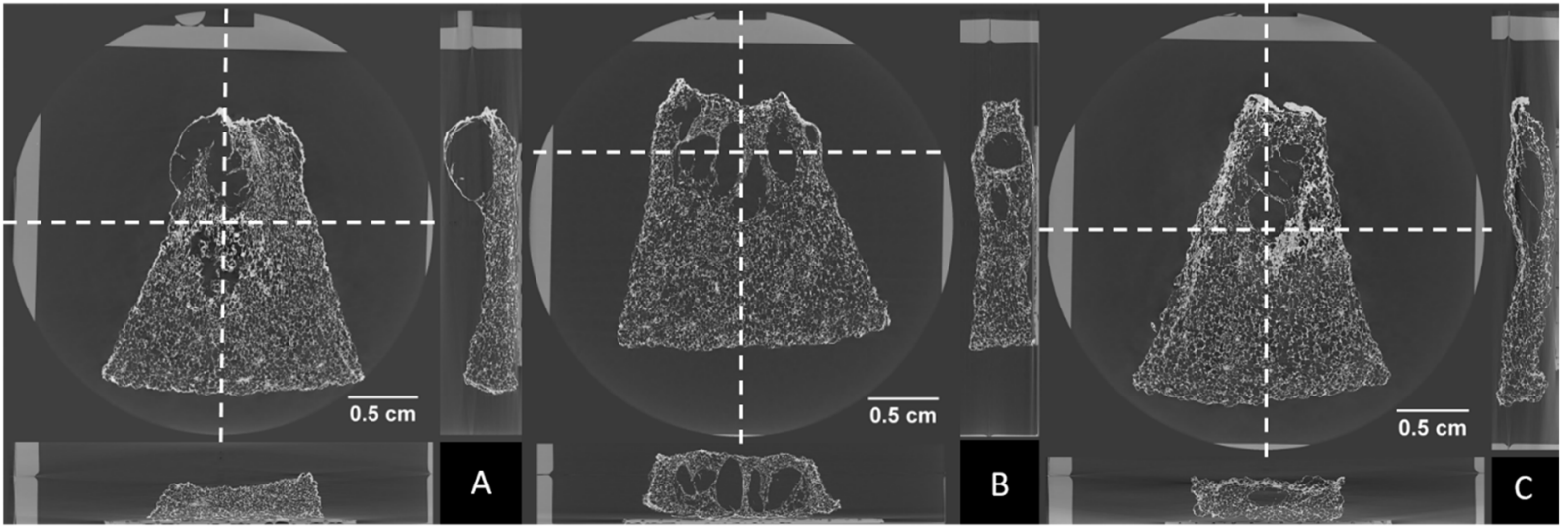

Figure 9: Apple pieces after a HAD0.5MVD combination drying process measured with micro-CT.

All three samples show puffing pores that are significantly larger than the usual pores of dried apples. Apart from the puffing pores, the majority of pores do not differ much in the pore structure as compared to pores formed in other processes. Puffing occurred mainly in the upper third (X-Y-Plane, top side), the location of major crust formation during the HAD0.5FD. Apparently, crusts in this area were sufficiently thick to hold back enough steam during MVD to allow for the required pressure build-up. These results show that a pre-HAD step 
can enable puffing for products that could not be puffed using only MVD. The exact amount of pre-HAD that is minimally needed for puffing depends on the product and would have to be evaluated in a subsequent study. In case of the used apple variety, the removal of $50 \%$ of the original moisture content was sufficient.

\section{Evaluation of serial combination drying processes - Rehydration measurements}

Rehydration of the puffed samples after HAD0.5MVD is comparable to FD samples (Figure 6b), as there is no significant difference independent of rehydration time. However, in comparison to single MVD, most WAC values increased. Especially during the first 10 minutes of rehydration the WAC is significantly higher, resulting in a high rehydration rate. The increased rehydration rates are potentially due to the puffing pores.

The rehydration values of samples obtained from HAD0.5FD processes are unexpectedly high. They are significantly higher than those of all other measured samples at all measured rehydration times. Usually, a crust (Figure 8) functions as diffusional barrier, slowing down rehydration. The unique structure of these samples (only five out of six surfaces are covered by a crust) may explain this unexpected behaviour: Rehydration can easily occur through the uncovered side. After rehydration, the jar-like crust around the product functions as a barrier during drip-off. As five out of six sides of the samples are covered by a crust, an increased water containment during drip-off appears possible, leading to distorted rehydration data in comparison to samples of other processes. Future studies on rehydration should focus on water holding capacity, too, in order to better compare HAD0.5FD samples with samples from other processes.

\section{Evaluation of serial combination drying processes - Colour and ingredient retention measurements}

Colour values for selected serial combination drying processes are provided in Figure 7. The colour of HAD0.5MVD-samples is comparably bright as the colour of MVD samples, but is characterized by lower red and higher yellow values. This leads to a less saturated appearance of the still dominant red colour. Samples of HAD0.5FD processes were comparably bright as FD samples. However, due to the higher yellow value, their appearance was less saturated concerning the red value, too. In summary, it can be stated that the colour of the combination dried samples was less saturated and, thus, the appearance of theses samples was less appealing compared to microwave-vacuum dried samples.

Figure 10 shows the retention of total ascorbic acid contents of the combination dried samples in comparison to samples dried with single drying processes.

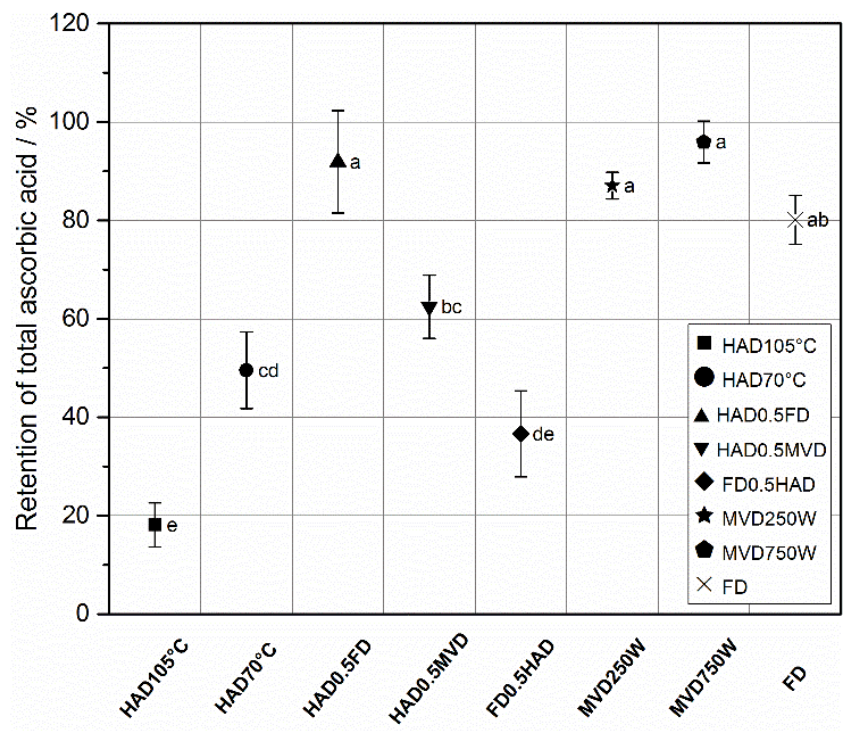

Figure 10: Retention of total ascorbic acid contents of apple pieces dried by combination processes in comparison to single drying processes. The error bars represent \pm standard deviation $\left(n=3\right.$, except $H A D 105^{\circ} \mathrm{C}$ : $n=2$ and HAD0.5FD: $n=4)$. Processes that do not share a similar letter are significantly different regarding their means of total ascorbic acid retention $(p<.05)$. HAD, hot-air drying;FD, freeze-drying; MVD, microwavevacuum drying.

Samples from HAD at 70 and $105{ }^{\circ} \mathrm{C}$ are characterized by a poor retention of their total ascorbic acid contents. Only $\sim 50 \%$ and $\sim 18 \%$ of the initial amounts were retained after drying. In contrast, the combination process 
HAD0.5FD results in excellent ascorbic acid retention $(\sim 90 \%$, no statistically significant difference to the content of the fresh product). This can be explained by the surface temperatures development during the HAD process as shown in Figure 11. This diagram shows both the retention of ascorbic acid (left ordinate axis) and the surface temperature of the samples (right ordinate axis) as a function of the relative moisture content of the samples. For both processes, ascorbic acid retention remains stable during HAD until a relative moisture content of $X / X_{0}=0.2$ is reached, followed by drastic ascorbic acid losses in the final step of the drying processes.

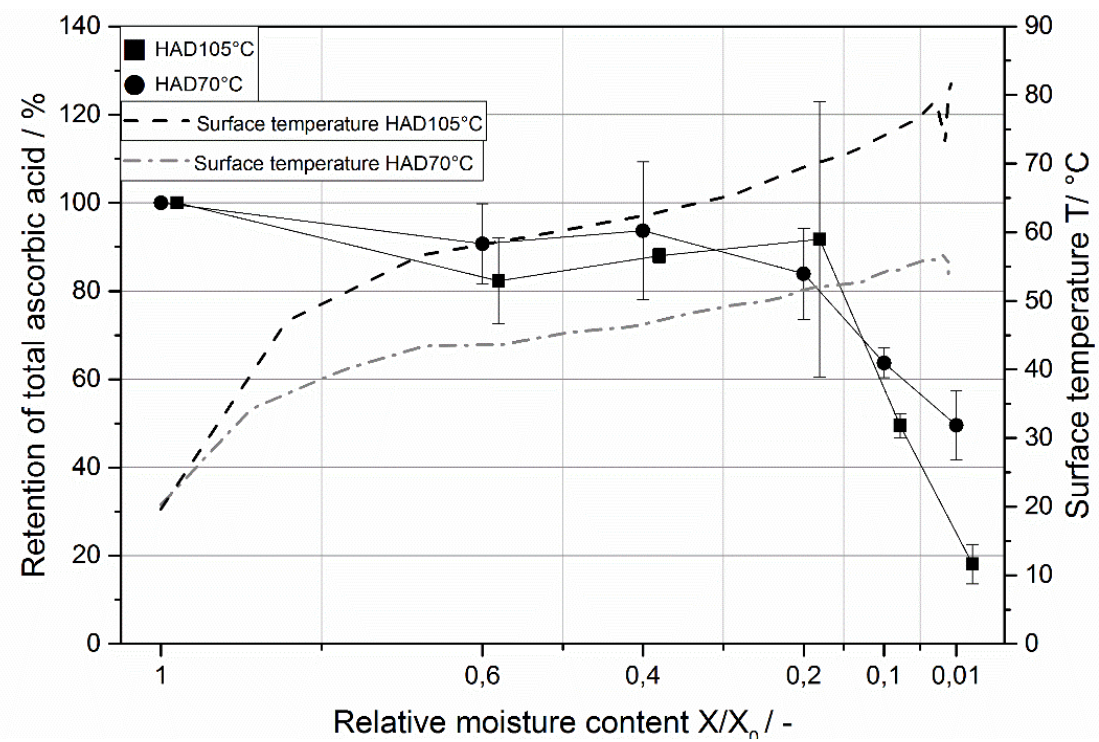

Figure 11: Retention of total ascorbic acid content during HAD at air temperatures of $70{ }^{\circ} \mathrm{C}$ and $105{ }^{\circ} \mathrm{C}$. Error bars are \pm standard deviation, where for $H A D 105^{\circ} \mathrm{C} n=2$ and for $H A D 70{ }^{\circ} \mathrm{C} n=3$. The surface temperature over time is additionally shown for both processes. HAD, hot air drying.

Thus, at the changeover point $\left(X / X_{0}=0.5\right)$ of a HAD0.5FD process, degradation of ascorbic acid has not yet taken place. During the subsequent FD process, the ascorbic acid retention remains stable, too. It is therefore not only possible to generate unique sample structures using a HAD0.5FD process, but also to effectively prevent ingredient degradation. As the thermal stress increases towards the end of a HAD process, the opposite order of processes $(\mathrm{FD} 0.5 \mathrm{HAD})$ results in a low ingredient retention of only $\sim 37 \%$, revealing no statistical difference to either HAD $70{ }^{\circ} \mathrm{C}$ or $\mathrm{HAD} 105^{\circ} \mathrm{C}$ (Figure 10). Considering the excellent ascorbic acid retention of a single FD process it is evident that ascorbic acid degradation occurs during the post-HAD process.

Ascorbic acid retention for the HAD0.5MVD process was determined to be about $62 \%$, demonstrating a moderate degradation (Figure 10). Because there is no observable degradation of ascorbic acid during both HAD until a relative moisture content of $X / X_{0}=0.5$ has been reached (see Figure 11) and the entire MVD processes (both power levels; Figure 10), this finding was somewhat unexpected. However, product temperature estimation over the course of this combination process may explain the reduced ascorbic acid retention. Figure 12 exemplarily compares sample surface temperatures of a HAD0.5MVD combination process and of a single MVD process as a function of the relative moisture content.

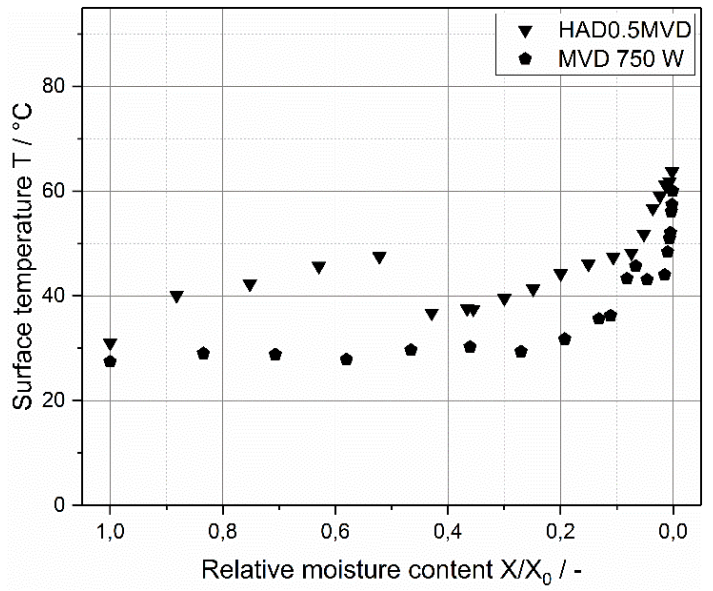


At the changeover point, the surface temperature of the product in the combination process is higher compared to the single MVD process at the same relative moisture content. Furthermore, during the final step of the drying process the product temperature remains higher for the combination process as compared to single MVD.

As mentioned earlier, ascorbic acid degradation during HAD starts at relative moisture contents $X / X_{0}$ of 0.2 . Consequently, combination processes involving a post-HAD process are characterized by strong ascorbic acid degradation, demonstrating a potential downside of combination processes, despite good structural properties and favorable color.

\section{CONCLUSION}

This study investigated the quality of apple samples for selected single and combination drying processes. Data were compared to those of carrots $^{[3]}$ in order to assess the impact of tissue structure on drying progress and resulting product properties. Drying times for single drying experiments were comparable for both plant materials. Nevertheless, due to the structural differences of the dried plant tissues (homogenous vs. heterogeneous) the drying front during FD of apples (from bottom to top, from outside to centre) moves differently compared to carrots (radially outwards).

Comparison of FD and MVD of apples regarding rehydration, pore structure, colour and ingredient retention revealed only small differences. Both single step processes resulted in uniform pore structures with no puffing. Different from FD a thin crust was formed around the MVD samples, likely explaining a slightly reduced rehydration rate of MVD samples compared to FD samples. Concerning the product colour, MVD samples were even more appealing than FD samples, showing an intense and more saturated purple-reddish colour. Ascorbic acid retention was almost complete for both processes.

Thus, combination of the two processes is not deemed necessary to obtain high-quality products. Nonetheless, a combination process can be used to create product structures that were impossible to create with single drying processes. Exemplarily, a pre-HAD process resulted in a thicker crust, allowing for the production of puffed products. In combination with a post-MVD process, puffing was realised during the MVD step. Puffing of apple slices/dices opens new avenues in product development. However, application of combination processes that involve HAD need to be carefully designed because drying temperatures greatly vary during a HAD process. If chosen as the final drying step, thermal stresses are likely to be much higher compared to other drying processes, resulting in negative product properties such as largely reduced ingredient retention.

In summary, if the influences of single drying steps are known, combination drying processes can be used for a targeted product design, depending on the further use of the product. Product design itself is hereby strongly dependent on the used product. We could show that homogeneous foods like apples behave different that homogeneous foods like carrots. In further studies, different products of the same characteristics should be analyzed to evaluate these correlations. Furthermore, studies with higher resolution concerning the micro-CT images should be performed to enable an automatic measurement routine for parameters like pore-size distribution or porosity.

\section{ACKNOWLEDGMENT}

The authors would like to express their thanks to Kerstin Sauther for supporting the drying experiments and to Sabine Engelhardt for supporting the micro-CT measurements.

\section{FUNDING}

This research project was supported by the German Ministry of Economics and Energy (via AIF) and FEI (Forschungskreis der Ernährungsindustrie e.V., Bonn) in the scope of project AiF $18250 \mathrm{~N}$.

\section{REFERENCES}

1. Liapis, A.I.; Bruttini, R. Freeze Drying. In Handbook of Industrial Drying, 4th ed; Mujumdar, A.S., Ed.; CRC Press: Boca Raton, 2015; 259-282.

2. Ciurzyńska, A.; Lenart, A. Freeze-Drying - Application in Food Processing and Biotechnology - A Review. Polish Journal of Food and Nutrition Sciences 2011, 61(3), 1688. 
3. Siebert, T.; Gall, V.; Karbstein, H.P.; Gaukel, V. Serial combination drying processes: A measure to improve quality of dried carrot disks and to reduce drying time. Drying Technology 2018, 36(13), 15781591.

4. Figiel, A. Drying kinetics and quality of beetroots dehydrated by combination of convective and vacuummicrowave methods. Journal Of Food Engineering 2010, 98(4), 461-470.

5. Duan, X.; Zhang, M.; Mujumdar, A.S. Study on a Combination Drying Technique of Sea Cucumber. Drying Technology 2007, 25(12), 2011-2019.

6. Hu, Q.G.; Zhang, M.; Mujumdar, A.S.; Xiao, G.N.; Sun, J.C. Drying of edamames by hot air and vacuum microwave combination. Journal Of Food Engineering 2006, 77(4), 977-982.

7. Pei, F.; Yang, W.j.; Shi, Y.; Sun, Y.; Mariga, A.; Zhao, L.y.; Fang, Y.; Ma, N.; An, X.x.; Hu, Q.h. Comparison of Freeze-Drying with Three Different Combinations of Drying Methods and Their Influence on Colour, Texture, Microstructure and Nutrient Retention of Button Mushroom (Agaricus bisporus) Slices. Food and Bioprocess Technology 2014, 7(3), 702-710.

8. Rother, M.; Steimle, P.; Gaukel, V.; Schuchmann, H.P. How to meet the freeze drying standard in combined drying processes: pre and finish drying of carrot dice. Drying Technology 2011, 29(3), 266-277.

9. Cui, Z.W.; Li, C.Y.; Song, C.F.; Song, Y. Combined microwave-vacuum and freeze drying of carrot and apple chips. Drying Technology 2008, 26(12), 1517-1523.

10. Baeghbali, V.; Niakousari, M.; Ngadi, M.O.; Hadi Eskandari, M. Combined ultrasound and infrared assisted conductive hydro-drying of apple slices. Drying Technology: An International Journal 2018, 13, 1-13.

11. Colucci, D.; Fissore, D.; Mulet, A.; Cárcel, J.A. On the investigation into the kinetics of the ultrasoundassisted atmospheric freeze drying of eggplant. Drying Technology 2017, 35(15), 1818-1831.

12. Szadzińska, J.; Łechtańska, J.; Pashminehazar, R.; Kharaghani, A.; Tsotsas, E. Microwave- and ultrasoundassisted convective drying of raspberries: Drying kinetics and microstructural changes. Drying Technology 2018, 1(3), 1-12.

13. Chong, C.H.; Figiel, A.; Law, C.; Wojdylo, A. Combined Drying of Apple Cubes by Using of Heat Pump, Vacuum-Microwave, and Intermittent Techniques. Food and Bioprocess Technology 2014, 7(4), 975-989.

14. Chua, K.J.; Chou, S.K. A comparative study between intermittent microwave and infrared drying of bioproducts. International Journal of Food Science \& Technology 2005, 40, 23-29.

15. Dehghannya, J.; Farshad, P.; Khakbaz Heshmati, M. Three-stage hybrid osmotic-intermittent microwaveconvective drying of apple at low temperature and short time. Drying Technology 2018, 36(16), 1982-2005.

16. Kumar, C.; Joardder, M.U.H.; Farrell, T.W.; Millar, G.J.; Karim, M.A. Mathematical model for intermittent microwave convective drying of food materials. Drying Technology 2015, 34(8), 962-973.

17. Kumar, C.; Karim, M.A.; Joardder, M.U.H. Intermittent drying of food products: A critical review. Journal Of Food Engineering 2014, 121, 48-57.

18. Pan, Y.K.; Zhao, L.J.; Mujumdar, A.S.; Kudra, T. Intermittent drying of carrot in a vibrated fluid bed: Effect on product quality. Drying Technology 1999, 17(10), 2323-2340.

19. Duan, X.; Zhang, M.; Li, X.L.; Mujumdar, A.S. Ultrasonically enhanced osmotic pretreatment of sea cucumber prior to microwave freeze drying. Drying Technology 2008, 26(4), 420-426.

20. Beaudry, C.; Raghavan, G.S.V.; Rennie, T.J. Microwave Finish Drying of Osmotically Dehydrated Cranberries. Drying Technology 2003, 21(9), 1797-1810.

21. Raghavan, G.S.V.; Silveira, A.M. Shrinkage characteristics of strawberries osmotically dehydrated in combination with microwave drying. Drying Technology 2001, 19(2), 405-414.

22. Siebert, T.; Zuber, M.; Engelhardt, S.; Baumbach, T.; Karbstein, H.P.; Gaukel, V. Visualization of crust formation during hot-air-drying via micro-CT. Drying Technology 2018, (accepted for publication).

23. Schrader, G.W.; Litchfield, J.B. Moisture profiles in a model food gel during drying: Measurement using magnetic resonance imaging and evaluation of the Fickian model. Drying Technology 1992, 10(2), $295-332$.

24. Shi, F.; Li, Y.; Wang, L.; Yang, Y.; Lu, K.; Wu, S.; MING, J. Measurement of moisture transformation and distribution in Tricholoma matsutake by low field nuclear magnetic resonance during the hot-air drying process. Journal of Food Processing and Preservation 2018, 42(3), e13565.

25. Kamal, T.; Song, Y.; Tan, Z.; Zhu, B.-W.; Tan, M. Effect of hot-air oven dehydration process on water dynamics and microstructure of apple (Fuji ) cultivar slices assessed by LF-NMR and MRI. Drying Technology: An International Journal 2019, 2, 1-14.

26. Wang, N.; Brennan, J.G. Changes in structure, density and porosity of potato during dehydration. Journal of Food Engineering 1995, 24(1), 61-76.

27. Voda, A.; Homan, N.; Witek, M.; Duijster, A.; van Dalen, G.; van der Sman, R.; Nijsse, J.; van Vliet, L.; van As, H.; van Duynhoven, J. The impact of freeze-drying on microstructure and rehydration properties of carrot. Food Research International 2012, 49(2), 687-693.

28. Rizzolo, A.; Vanoli, M.; Cortellino, G.; Spinelli, L.; Contini, D.; Herremans, E.; Bongaers, E.; Nemeth, A.; Leitner, M.; Verboven, P.; et al. Characterizing the tissue of apple air-dried and osmo-air-dried rings by X- 
$\mathrm{CT}$ and OCT and relationship with ring crispness and fruit maturity at harvest measured by TRS. Innovative Food Science \& Emerging Technologies 2014, 24, 121-130.

29. Calín-Sánchez, Á.; Kharaghani, A.; Lech, K.; Figiel, A.; Carbonell-Barrachina, Á.A.; Tsotsas, E. Drying Kinetics and Microstructural and Sensory Properties of Black Chokeberry (Aronia melanocarpa) as Affected by Drying Method. Food and Bioprocess Technology 2015, 8(1), 63-74.

30. van Dalen, G.; Qiu, J.; Khalloufi, S. Micro-CT imaging and analysis of eggplants and carrots during air drying. Bruker micro-CT user meeting 2015.

31. van Dalen, G.; Nootenboom, P.; van Vliet, L.J.; Voortman, L.; Esveld, E. 3D imaging, analysis and modelling of porous cereal products using X-ray microtomography. Image Analysis Stereology 2007, 26, 169-177.

32. Rahman, M.M.; Kumar, C.; Joardder, M.U.H.; Karim, M.A. A micro-level transport model for plant-based food materials during drying. Chemical Engineering Science 2018, 187, 1-15.

33. Rahman, M.M.; Joardder, M.U.H.; Karim, A. Non-destructive investigation of cellular level moisture distribution and morphological changes during drying of a plant-based food material. Biosystems Engineering 2018, 169, 126-138.

34. Siebert, T.; Zuber, M.; Hamann, E.; Baumbach, T.; Karbstein, H.P.; Gaukel, V. Micro-CT visualization of structure development during freeze-drying processes. Drying Technology, (submitted).

35. Sham, P.W.Y.; Scaman, C.H.; Durance, T.D. Texture of vacuum microwave dehydrated apple chips as affected by calcium pretreatment, vacuum level, and apple variety. Journal of Food Science 2001, 66(9), 1341-1347.

36. Lewicki, P.P.; Pawlak, G. Effect of Drying on Microstructure of Plant Tissue. Drying Technology 2003, 21(4), 657-683.

37. Nguyen Do Trong, N.; Rizzolo, A.; Herremans, E.; Vanoli, M.; Cortellino, G.; Erkinbaev, C.; Tsuta, M.; Spinelli, L.; Contini, D.; Torricelli, A.; et al. Optical properties-microstructure-texture relationships of dried apple slices: Spatially resolved diffuse reflectance spectroscopy as a novel technique for analysis and process control. Innovative Food Science \& Emerging Technologies 2014, 21, 160-168.

38. Zuber, M.; Laßß, M.; Hamann, E.; Kretschmer, S.; Hauschke, N.; van de Kamp, T.; Baumbach, T.; Koenig, T. Augmented laminography, a correlative 3D imaging method for revealing the inner structure of compressed fossils. Scientific reports 2017, 7, 41413.

39. Santos, P.H.S.; Silva, M.A. Retention of Vitamin C in Drying Processes of Fruits and Vegetables - A Review. Drying Technology 2008, 26(12), 1421-1437.

40. Sánchez-Mata, M.C.; Cámara-Hurtado, M.; Díez-Marqués, C.; Torija-Isasa, M.E. Comparison of highperformance liquid chromatography and spectrofluorimetry for vitamin $\mathrm{C}$ analysis of green beans (Phaseolus vulgaris L.). European Food Research and Technology 2000, 210(3), 220-225.

41. Tai, A.; Gohda, E. Determination of ascorbic acid and its related compounds in foods and beverages by hydrophilic interaction liquid chromatography. Journal of chromatography. B, Analytical technologies in the biomedical and life sciences 2007, 853(1-2), 214-220.

42. Le Loch-Bonazzi, C.; Wolff, E.; Gilbert, H. Quality of dehydrated cultivated mushrooms (Agaricus bisporus): a comparison between different drying and freeze-drying processes. Lebensmittel Wissenschaft und Technologie 1992, 25, 334-339.

43. Lewicki, P.P. Some remarks on rehydration of dried foods. Journal of Food Engineering 1998, 36(1), 8187.

44. Rueden, C.T.; Schindelin, J.; Hiner, M.C.; DeZonia, B.E.; Walter, A.E.; Arena, E.T.; Eliceiri, K.W. ImageJ2: ImageJ for the next generation of scientific image data. BMC bioinformatics 2017, 18(1), 529.

45. Schindelin, J.; Arganda-Carreras, I.; Frise, E.; Kaynig, V.; Longair, M.; Pietzsch, T.; Preibisch, S.; Rueden, C.; Saalfeld, S.; Schmid, B.; et al. Fiji: an open-source platform for biological-image analysis. Nature Methods 2012, 9(7), 676-682.

46. Buades, A.; Coll, B.; Morel, J.-M. Non-Local Means Denoising. Image Processing On Line 2011, 1, 208212.

47. Darbon, J.; Cunha, A.; Chan, T.F.; Osher, S.; Jensen, G.J. Fast nonlocal filtering applied to electron cryomicroscopy. Proceedings / IEEE International Symposium on Biomedical Imaging: from nano to macro 2008, 1331-1334.

48. Gaukel, V.; Siebert, T.; Erle, U. Microwave-assisted drying. In The Microwave Processing of Foods, 2nd ed; Regier, M., Knoerzer, K., Schubert, H., Eds.; Elsevier Science: Kent, 2017; 152-178.

49. Lapsley, K.G.; Escher, F.E.; Hoehn, E. The Cellular Structure of Selected Apple Varieties. Food Structure 1992, 11, 339-349.

50. Duan, X.; Ren, G.Y.; Zhu, W.X. Microwave Freeze Drying of Apple Slices Based on the Dielectric Properties. Drying Technology 2012, 30(5), 535-541.

51. Hammami, C.; René, F.; Marin, M. Process-quality optimization of the vacuum freeze-drying of apple slices by the response surface method. International Journal of Food Science \& Technology 1999, 34(2), 145-160. 
52. Payne, F.A.; Taraba, J.L.; Saputra, D. A Review of Puffing Processes for Expansion of Biological Products. Journal of Food Engineering 1989, 10, 183-197.

53. Yi, J.-Y.; Zhou, L.-Y.; Bi, J.-F.; Wang, P.; Liu, X.; Wu, X.-Y. Influence of number of puffing times on physicochemical, color, texture, and microstructure of explosion puffing dried apple chips. Drying Technology 2015, 34(7), 773-782. 